\title{
Double tracer gas single-breath washout: promising for clinics or just a toy for research?
}

\author{
Philipp Latzin ${ }^{1}$ and Bruce Thompson²
}

Affiliations: 'University Children's Hospital Basel (UKBB), University of Basel, Basel, Switzerland. ${ }^{2}$ Allergy, Immunology and Respiratory Medicine, The Alfred Hospital, Dept of Medicine, Monash University, Melbourne, Australia.

Correspondence: Philipp Latzin, University Children's Hospital (UKBB), Spitalstrasse 33, Basel, Switzerland. E-mail: Philipp.Latzindukbb.ch

0

@ERSpublications

Double tracer gas single-breath washout is a promising test to assess ventilation inhomogeneity in the lung periphery http://ow.ly/zW41z

Ventilation inhomogeneity reflects the efficiency of gas transport in both central, convection-dependent and peripheral, diffusion-dependent airways. In recent years, there has been a renaissance of studies using inertgas washout to assess ventilation inhomogeneity. This trend is due to promising results of multiple-breath washout (MBW) tests in different populations with various lung diseases, such as cystic fibrosis [1] and asthma [2]. Even though the MBW is becoming more widely used and better standardised, the long duration of the test is a potential impediment in daily clinical practice and in patients with severe lung disease. One alternative is to study the ventilation distribution based on one single breath, by performing the so-called single-breath washout (SBW). The SBW test is not new, having been done for the first time more than 60 years ago, by using 100\% oxygen to study the washout of the resident nitrogen $\left(\mathrm{N}_{2}\right)$ [3], or by using a double tracer gas (DTG) mixture, such as helium $(\mathrm{He})$ and sulfur hexafluoride $\left(\mathrm{SF}_{6}\right)$ [4]. Usually the SBW test is done during a vital capacity manoeuvre (VC-SBW) and there is a recent European Respiratory Society/American Thoracic Society consensus statement on how to perform the VC-SBW test [5]. A clear disadvantage of the VC-SBW test is the dependence on the vital capacity manoeuvre. This is particularly a problem in children younger than 12 years and, in general, results might be influenced by restricted ability of patients performing the manoeuvre [5]. Furthermore, it has been shown that deep inspiration influences expiratory slopes $[6,7]$. In addition, analysis of $\mathrm{SF}_{6}$ and $\mathrm{He}$ needs a mass spectrometer, which is not practical for clinical use.

These drawbacks are overcome by a recently developed SBW test that is performed during tidal breathing and uses a DTG mixture of $\mathrm{He}_{\mathrm{e}}$ and $\mathrm{SF}_{6}$ to assess ventilation inhomogeneity without the need for a mass spectrometer. The test was validated using a commercially available piece of equipment [8], and promising results with regards to differences between children with cystic fibrosis and mild asthma and healthy controls have been found $[9,10]$. The test is based on unequal distribution of the two tracer gases due to their different diffusion properties. The main outcome, phase III slope (SIII), is based on the molar mass of both gases and is thought to reflect more peripheral ventilation inhomogeneity, as the DTG mixture presumably does not separate during bulk flow in convective large airways but separates into $\mathrm{He}$ and $\mathrm{SF}_{6}$ in diffusion-dependent peripheral airways [11].

In this issue of the European Respiratory Journal, HUSEMANN et al. [12] report on the variability and reproducibility of this DTG-SBW technology in healthy adult subjects and patients with chronic obstructive pulmonary disease (COPD). Not only is this the first study applying this new tidal test in adult patients, it is

Received: June 182014 | Accepted after revision: July 302014

Conflict of interest: None declared.

Copyright (C)ER 2014 
also the first to show differences in test outcomes between COPD and controls. In addition to studying DTG-SBW, the authors assessed the repeatability of different MBW outcomes, such as lung clearance index (LCI), Scond and Sacin [12]. Scond and Sacin are derived from the SIII from MBW, and have been found to distinguish between conductive (Scond) and acinar ( acin) ventilation inhomogeneity. In accordance with the pathophysiological background, the authors report an association of Sacin with DTG-SBW outcomes, both of which are thought to reflect more peripheral ventilation inhomogeneity.

The study has been performed thoroughly and the authors present all results, associations of outcome parameters with breathing pattern, and possible drawbacks of the current setup, in a detailed way. Interestingly, they find an association between results of SIII from the DTG-SBW and transfer factor of the lung for carbon monoxide. This indicates the new DTG-SBW test might be useful to also assess emphysematous lung regions, as it has been shown before for the VC-SBW [3]. This adds to the existing evidence suggesting that both SBW of different gases and Sacin from MBW have the ability to discriminate emphysema from normal subjects, and bronchiolitis obliterans syndrome in lung transplant recipients $[4,13-15]$. These patient groups further demonstrate the usefulness of the inert gas washout test beyond cystic fibrosis and asthma [16-18]. Despite those promising results, it is unclear how the new test fits in exactly with current measurements of ventilatory heterogeneity. Furthermore, it is still unclear exactly what type of ventilatory heterogeneity (convection-dependent inhomogeneity or diffusion-convection-dependent heterogeneity) the test is measuring. One clear advantage of the test is the better repeatability compared with those specific markers (Scond and Sacin) from MBW as shown by HuSEMANN et al. [12], which is a bit surprising given the amount of breaths used to calculate Scond. Another advantage over MBW is the short duration. Despite approaches to shorten MBW tests [19], a test of a single breath will always be shorter than a test involving multiple breaths. Most impressive, however, is how well the results resemble data from VC-SBW using mass spectrometry [20], although in the current study, an aggregated molar mass signal was measured and the test was performed during free tidal breathing.

There are some theoretical and methodological issues of this new DTG-SBW test that currently preclude it being used for clinical decision making. These include 1) the exact dependence on the underlying breathing pattern. The authors suggest that factors other than breathing pattern influence results; however, this has been studied cross-sectionally only and never been assessed systematically for this test. Studies using VC-SBW indicate that this might even be different for children and adults [21]. 2) The exact underlying anatomical changes remain unclear. Despite preliminary results using VC-SBW showing associations [22], more studies examining the association with measures of lung structure or imaging are needed. 3) Some technical issues need to be resolved, as pointed out by the authors with regards to, for example, spikes at beginning of inspiration of the test gas. This also includes the availability of commercial software for analysis. 4) The exact contribution of $\mathrm{N}_{2}$ to the overall signal is not understood. Strictly speaking, the DTG-SBW procedure contains a partial washout of lung inherent nitrogen while the dual-tracer gas mixture is in- and exhaled. As molar mass measures only the sum of all gases, theoretically, the $\mathrm{N}_{2}$ fraction may also influence results.

Overall, the article by HUSEMANN et al. [12] underlines that the DTG-SBW is a promising new test to assess ventilation inhomogeneity in the lung periphery. Whether it will find its way into clinics or is just another tool for researchers is unknown. In any case, its easy and fast application, and widespread availability, make it attractive and will help to gather more data quickly in order to answer this in the future. There are now more than 10 measures of ventilation heterogeneity derived by either SBW or MBW tests. LCI, Scond and Sacin have, at this stage, led the race as validated and clinically useful tests; however, new measures, such as DTG-SBW and others, have yet to find their place in the clinic. These measures may indeed be demonstrated to be more reliable, practical measures of ventilation heterogeneity. However, we cannot lose sight of the fact that the physiological outcome that we are trying to measure is ventilation heterogeneity. Ventilation heterogeneity can mean many things depending on the test that we use (e.g. nuclear medicine scans) [23]. Measures of specific ventilation, convection-dependent and diffusion-convection-dependent heterogeneity have shown to be highly clinically relevant. The test that measures these physiological abnormalities with the greatest accuracy, precision and ease for the patient will be the one quite rightly adopted in the clinic.

\section{References}

Singer F, Kieninger E, Abbas C, et al. Practicability of nitrogen multiple-breath washout measurements in a pediatric cystic fibrosis outpatient setting. Pediatr Pulmonol 2013; 48: 739-746.

2 Thompson BR, Douglass JA, Ellis MJ, et al. Peripheral lung function in patients with stable and unstable asthma. J Allergy Clin Immunol 2013; 131: 1322-1328.

3 Fowler WS. Lung function studies; uneven pulmonary ventilation in normal subjects and in patients with pulmonary disease. J Appl Physiol 1949; 2: 283-299. 
Georg J, Lassen NA, Mellemgaard K, et al. Diffusion in the gas phase of the lungs in normal and emphysematous subjects. Clin Sci 1965; 29: 525-532.

5 Robinson PD, Latzin P, Verbanck S, et al. Consensus statement for inert gas washout measurement using multipleand single- breath tests. Eur Respir J 2013; 41: 507-22.

6 Paiva M, van Muylem A, Ravez P, et al. Preinspiratory lung volume dependence of the slope of the alveolar plateau. Respir Physiol 1986; 63: 327-338.

7 Cooper DM, Mellins RB, Mansell AL. Changes in distribution of ventilation with lung growth. J Appl Physiol Respir Environ Exerc Physiol 1981; 51: 699-705.

8 Singer F, Stern G, Thamrin C, et al. Tidal volume single breath washout of two tracer gases-a practical and promising lung function test. PLoS One 2011; 6: e17588.

9 Singer F, Stern G, Thamrin C, et al. A new double-tracer gas single-breath washout to assess early cystic fibrosis lung disease. Eur Respir J 2013; 41: 339-345.

10 Singer F, Abbas C, Yammine S, et al. Abnormal small airways function in children with mild asthma. Chest 2014; 145: 492-499.

11 Abbas C, Singer F, Yammine S, et al. Treatment response of airway clearance assessed by single-breath washout in children with cystic fibrosis. J Cyst Fibros 2013; 12: 567-574.

12 Husemann K, Berg N, Engel J, et al. Double tracer gas single-breath washout: reproducibility in healthy subjects and COPD. Eur Respir J 2014; 44: 1210-1222.

13 Thompson BR, Hodgson YM, Kotsimbos T, et al. Bronchiolitis obliterans syndrome leads to a functional deterioration of the acinus post lung transplant. Thorax 2014; 69: 487-488.

14 Verbanck S, Schuermans D, Meysman M, et al. Noninvasive assessment of airway alterations in smokers: the small airways revisited. Am J Respir Crit Care Med 2004; 170: 414-419.

15 Van Muylem A, Antoine M, Yernault JC, et al. Inert gas single-breath washout after heart-lung transplantation. Am J Respir Crit Care Med 1995; 152: 947-952.

16 Downie SR, Salome CM, Verbanck S, et al. Effect of methacholine on peripheral lung mechanics and ventilation heterogeneity in asthma. J Appl Physiol (1985) 2013; 114: 770-777.

17 Nguyen TT, Thia LP, Hoo AF, et al. Evolution of lung function during the first year of life in newborn screened cystic fibrosis infants. Thorax 2014; 69: 910-917.

18 Kieninger E, Singer F, Fuchs O, et al. Long-term course of lung clearance index between infancy and school-age in cystic fibrosis subjects. J Cyst Fibros 2011; 10: 487-490.

19 Yammine S, Singer F, Abbas C, et al. Multiple-breath washout measurements can be significantly shortened in children. Thorax 2013; 68: 586-587.

20 Engel LA, Paiva M, Siegler DI, et al. Dual tracer single breath studies of gas transport in the lung. Respir Physio 1979; 36: 103-119.

21 Van Muylem A, Paiva M, Baran D, et al. Structural change of the acinus during growth assessed by single-breath tracer gas washouts. Pediatr Pulmonol 1996; 22: 230-235.

22 Van Muylem A, De Vuyst P, Yernault JC, et al. Inert gas single-breath washout and structural alteration of respiratory bronchioles. Am Rev Respir Dis 1992; 146: 1167-1172.

23 Horn FC, Deppe MH, Marshall H, et al. Quantification of regional fractional ventilation in human subjects by measurement of hyperpolarized ${ }^{3} \mathrm{He}$ washout with 2D and 3D MRI. J Appl Physiol (1985) 2014; 116: 129-139. 